\title{
Graft patency at 3 months after off- and on-pump coronary bypass surgery: a randomized trial
}

\author{
Lokeswara Rao Sajja $^{1,2} \cdot$ Kunal Sarkar ${ }^{3} \cdot$ Gopichand Mannam $^{1} \cdot$ Venkata Krishna Kumar Kodali ${ }^{4}$. \\ Chandrasekar Padmanabhan ${ }^{5} \cdot$ Sanjeeth Peter $^{6} \cdot$ Anvay Mulay $^{7} \cdot$ Prashanthi Beri $^{8}$
}

Received: 18 June 2019 / Revised: 17 August 2019 / Accepted: 1 September 2019 / Published online: 28 October 2019

(C) The Author(s) 2019

\begin{abstract}
Purpose Coronary artery bypass grafting (CABG) is performed either with the aid of cardiopulmonary bypass (on-pump) or without cardiopulmonary bypass (off-pump). There is a scarcity of angiographic data to support the non-inferiority of off-pump technique to on-pump technique. The objective of this study is to ascertain the non-inferiority of off-pump CABG when compared to on-pump CABG in terms of angiographically assessed graft patency at 3 months.

Methods A total of 320 patients with multivessel coronary artery disease were enrolled in a multicenter prospective randomized trial either to on-pump CABG $(n=162)$ or off-pump CABG $(n=158)$ between March 2016 through March 2017. Graft patency was evaluated by using either multidetector computerized tomographic angiography or conventional coronary angiography at 3 months. The major adverse cardiac and cardiovascular events (MACCE) were also analyzed at 3 months.

Results The median number of grafts per patient in off-pump was 3.00 (Q1:3.00 and Q3:4.00) vs on-pump 4.00 (Q1:3.00 to Q3:4.00), and the mean number of grafts per patient was lower in the off-pump CABG at $3.45 \pm 0.75 \mathrm{vs} 3.64 \pm 0.70$ in the onpump CABG $(p=0.01)$. There was no significant difference in mortality at 3 months between the off-pump $(0.63 \%)$ and onpump groups $(1.85 \%)$ with $p$ value of 0.62 . The cumulative combined MACCE showed significant difference between off-pump group $(0.63 \%)$ and on-pump group $(5.55 \%), p=0.01$. Follow-up angiograms were done in 239 (75\%) patients with 120 offpump and 119 in the on-pump group. The analysis was also done regarding graft patency in a graded manner-when analysis of A (excellent) grafts vs B (stenosed) grafts and O (occluded) grafts were made, there was no statistically significant difference in overall graft patency at 3 months between on-pump [376/429 grafts (87.6\%)] and off-pump [366/420 grafts (87.1\%)] groups $(p=0.82)$. The patency rates were similar among bypass conduits (left internal thoracic artery (ITA) in off-pump (91.4\%) vs onpump $(92.9 \%) p=0.66$, right ITA in off-pump $(82.1 \%)$ vs on-pump $(81.8 \%) p=0.97$, radial artery in off-pump (84.4\%) vs onpump $(82.6 \%) p=0.81$; saphenous vein in off-pump (85.8\%) vs on-pump $(86.3 \%), p=0.86$ and among 3 coronary territories.
\end{abstract}

The abstract was presented as an oral presentation at AATS 98th Annual Meeting 2018, San Diego, CA

Electronic supplementary material The online version of this article (https://doi.org/10.1007/s12055-019-00869-0) contains supplementary material, which is available to authorized users.

Lokeswara Rao Sajja

sajjalr@yahoo.com

1 Division of Cardiothoracic Surgery, STAR Hospitals, Road no. 10, Banjara Hills, Hyderabad, Telangana 500 034, India

2 Division of Cardiovascular Surgical Research, Sajja Heart Foundation, Srinagar Colony, Hyderabad 500073, India

3 Division of Cardiothoracic Surgery, Medica Superspeciality Hospital, 127-Mukundapur, EM bypass, Kolkata 700025, India
4 Division of Cardiothoracic Surgery, Krishna Institute of Medical Sciences, 1-8-31/1,Minister Road, Secunderabad, Telangana 500003, India

5 Division of Cardiothoracic Surgery, G Kuppuswamy Naidu Memorial Hospital, Pappanaicken Palayam, Coimbatore 641 037, India

6 Division of Cardiothoracic Surgery, DDMM Heart Institute, Mission Road, Nadiad, Gujarat 387002, India

7 Division of Cardiothoracic Surgery, Fortis Hospital, Multi-Specialty Hospital Mulund West, Mumbai 400078, India

8 Division of Clinical Research, Sajja Heart Foundation, Srinagar Colony, Hyderabad 500073, India 
Conclusions Off-pump CABG is non-inferior to on-pump CABG in terms of overall graft patency at 3 months and was associated with a fewer combined cumulative MACCE compared to on-pump CABG.

Keywords Coronary artery bypass grafting $(\mathrm{CABG}) \cdot$ Multidetector computerized tomographic angiography $\cdot$ Coronary angiography

\section{Introduction}

CABG is the preferred method of treatment for patients with multivessel coronary artery disease $(\mathrm{CAD})$ and is performed either with the aid of cardiopulmonary bypass (onpump) or without cardiopulmonary bypass (off-pump) [1]. Since the beginning of off-pump CABG, there are concerns regarding the quality of coronary anastomosis and the completeness of revascularization, particularly of the lateral wall of the left ventricle. Currently, about $10-20 \%$ of CABG procedures are being performed using off-pump technique in North America and Europe [2]. The data on lower graft patency in patients undergoing off-pump CABG emanates from centers with low adoption of off-pump technique [1,3-5], but graft patency was reported to be similar with either off-pump or on-pump technique by the surgeons whose adoption rate of off-pump technique was over $50 \%$ of the cases [6].

Off-pump CABG is adopted in over $50 \%$ of the patients in India [7], whereas it is on decline in the Western world. In India, several surgeons adopt an on-pump strategy only when the patient is ineligible for off-pump because of hemodynamic instability or diffuse CAD with small caliber vessels. This study was contemplated to assess whether the quality of revascularization in terms of graft patency in off-pump is noninferior to that of on-pump CABG by angiographic assessment when the procedure is performed by the surgeons with off-pump adoption rates in excess of $50 \%$ and have performed over 250 off-pump CABG procedures and negotiated the learning curve prior to participation in the trial.

\section{Patients and methods}

This Prospective Randomized comparison of Off-pump and On-pump Multivessel coronary artery bypass surgery To Evaluate outcomes and graft patency (PROMOTE patency) trial was conducted between March 2016 through March 2017. The patients who met the inclusion and exclusion criteria were randomized in the ratio of 1:1 using block randomization, with a block size as 4 , using software SAS version 9.2. A total of 321 patients were randomized and 320 patients (recruitment ranged from 26 to 56 patients per surgeon) were enrolled to either on-pump $(n=162)$ or offpump $(n=158)$ CABG at 6 centers by 7 surgeons in India.
The PROMOTE patency trial was registered in the Clinical Trials Registry of India (CTRI/2017/10/010030). This trial complies with the principles of The Declaration of Helsinki and was approved by the institutional ethics committees by the participating institutions and all patients gave an informed written consent to participate in the study.

The inclusion criteria were male or female aged $\geq 21$ years and $\leq 70$ years, and multivessel CAD, with triple vessel disease or left main coronary artery (LMCA) stenosis, requiring isolated $\mathrm{CABG}$ and with left ventricular ejection fraction (LVEF) of $\geq 40 \%$. Exclusion criteria were CABG with concomitant procedures, contra-indications to either off-pump or on-pump CABG, chronic atrial fibrillation, and serum creatinine $>1.3 \% \mathrm{mg} / \mathrm{dL}$. Graft patency was assessed at 3 months by either 128 slice multidetector computed tomographic angiography (MDCT) or conventional catheter coronary angiography (CAG). Graft patency was evaluated on the basis of type of conduit and coronary artery territory, as well as the number of anastomoses patent per patient. The graft evaluation was made similar to Fitzgibbon grading of grafts [8]: A (excellent) vs B (stenosed) and O (occluded). In this study, graft patency was graded as A (excellent patency) vs B (partially stenosed) and $\mathrm{O}$ (occluded) grafts. All the graft angiograms (MDCT and CAG) were analyzed at the trial coordinating center by a single team comprising of a cardiologist and a radiologist with knowledge of the number and distribution of grafts performed but blinded for the type of revascularization technique used(on-pump or off-pump). The occurrence of MACCE was recorded as secondary outcomes at first and third month postoperatively.

Surgeons who had performed more than $500 \mathrm{CABG}$ procedures ( 250 procedures of each technique) during the 3 years prior to the trial with $50 \%$ adoption of the off-pump technique and who had a post $\mathrm{CABG}$ mortality rate $\leq 3 \%$ for isolated primary CABG were selected for this study.

\section{Statistical methods}

In order to detect a difference of $10 \%$ in patency rates between off-pump and on-pump CABG, with a power of $90 \%$ and one tailed, 5\% significance level, and assuming patency rates of $80 \%$ and $90 \%$, a total of 1050 distal graft anastomoses (525 grafts per group) were required. Since each patient had at least three grafts, a total of 310 patients would be necessary (155 patients in each arm.) To compensate for eventual dropouts of 
$10 \%$, the study kept an enrolment target of 350 patients (175 patients in each arm).

ROOBY trial [1] reported lower graft patency with offpump compared to on-pump CABG (82.6 vs $87.8 \%$, respectively; $\left.p \_0.001\right)$ at 1 year. Khan et al. [3] reported the overall patency rate for grafts performed with on-pump was significantly higher than the patency rate for those performed offpump (98 vs $88 \%, p=0.002$ ) [absolute difference of $10 \%$ with 95\% CI (3.8 to 16.2)] at 3 months. The sample size in this study was calculated based on the graft patency of the above trials. The current study is a non-inferiority trial, and hence, the null hypothesis is formulated as H0: The graft patency rate for off-pump is inferior to on-pump graft patency rate by a clinically relevant patency rate of $10 \%$. HA: The graft patency rate for off-pump is non-inferior to the graft patency rate of onpump or, alternatively is formulated as $\mathrm{H} 0$ : The difference in the graft patency rate between off-pump and on-pump is (10\%) HA: The difference in the graft patency rate between off-pump and on-pump is (>-10\%). The required sample size (n) for each group has been arrived assuming an $\alpha=5 \%$ or a confidence level (1-a) of $95 \%, \beta=10 \%$ or a power $(1-\beta)$ of $90 \%$, the non-inferiority clinical margin (d) of $10 \%$, and $\mathrm{Zx}$ is the standard normal variate for a one sided $\mathrm{x}$.

Statistical analysis was performed by the trial coordinating center using software SAS version 9.2. Continuous variables have been expressed as median, mean \pm standard deviation. The categorical variables have been expressed as raw numbers and percentages. The differences were analyzed with chisquare, Fisher exact test (if cell frequency was less than 5), and two sample $t$ test. The statistical significance for all the tests was accepted at a probability level $<0.05$.

\section{Preoperative optimization of medical therapy}

Withdrawal of antiplatelet drugs was done 4 days prior to surgery and low molecular weight heparin was started.

\section{Surgical techniques}

Premedication, anesthetic protocols, surgical access to the heart via a standard median sternotomy, conduit harvesting techniques, and distal and proximal anastomotic techniques were similar between the groups. Heparin dose was adjusted to achieve target activated clotting time of $>480 \mathrm{~s}$ and $>350 \mathrm{~s}$ for on-pump and off-pump groups respectively. Heparin was reversed using protamine at a dose of $1.3 \mathrm{mg} / 100 \mathrm{IU}$ heparin in both the groups. The surgical techniques of revascularization were followed as described earlier [9].

On-pump technique Myocardial protection was achieved by cold $\left(4^{\circ} \mathrm{C}\right)$ antegrade blood and potassium cardioplegia. The distal coronary anastomoses were performed with either 7-0 or 8-0 polypropylene continuous suturing techniques and the proximal anastomoses were performed using 6-0 polypropylene sutures as described earlier [9].

Off-pump technique The method of exposure and stabilization of heart to perform distal coronary anastomoses consisted of the technique previously described [9]. Target artery stabilization was achieved with vacuum stabilizers - Octopus 4 or Evolution (Medtronic Inc., Minneapolis, MN, USA) or ACROBAT-i Stabilizer System (Maquet GmbH \& Co, Rastatt, Germany), and clearview intra coronary shunts were used [Medtronic Inc. Minneapolis, MN, USA] in all coronary arteries measuring more than $1.25 \mathrm{~mm}$ in diameter while constructing the distal anastomoses. Visualization of the anastomotic area was enhanced by using humidified carbon dioxide blower/mister (Medtronic Inc. Grand Rapids, Mich) to disperse the blood from the site of distal anastomosis. Postoperatively, all patients received dual antiplatelet therapy (aspirin $75 \mathrm{mg}$, clopidogrel $75 \mathrm{mg}$ ) once daily. Patients in whom endarterectomy was performed on any of the coronary arteries received acenocoumarol with target international normalized ratio (INR) of around 2.0 for 3 months.

\section{Outcome measures}

The primary endpoint was graft patency at 3 months, assessed by either 128 slice MDCT or CAG. Graft assessment was done similar to Fitzgibbon grading of ABO grade grafts [8]. Grade A graft was defined as an excellent graft with unimpaired runoff, and grade B graft was defined as stenosis reducing caliber of proximal or distal anastomoses or trunk to $50 \%$ of the grafted coronary artery. Grade $\mathrm{O}$ graft was defined as absence of contrast material along the course of the graft, through the graft anastomosis to the native coronary artery or to the following graft segment and native vessel. In sequential bypass grafts, each anastomosis of the graft was counted as an individual graft. The secondary end points were death, nonfatal cerebrovascular stroke/accident (CVS/CVA), myocardial infarction (MI), and repeat revascularisation at 30 days and 3 months postoperatively. The occurrence of MACCE was defined as death, MI, or CVS at 30 days and 3 months after CABG. The terminologies used in the study have been defined. Cardiovascular (CV) death: All deaths were considered cardiovascular unless a specific noncardiovascular cause is evident (e.g., malignancy). CVS: new acute focal neurological deficit (except for subarachnoid hemorrhage which may not be focal) thought to be of vascular origin with signs or symptoms lasting greater than $24 \mathrm{~h}$. MI perioperative (within $24 \mathrm{~h}$ of surgery): new pathologic $\mathrm{Q}$ waves with documented new wall motion abnormalities other than septal wall or cardiac markers $=10 x U L N$ (upper limit of normal). MI nonperioperative (later than $24 \mathrm{~h}$ of after surgery): electrocardiogram (ECG) changes consistent with infarction (new significant $\mathrm{Q}$ waves in two contiguous leads in the absence 
of previous left ventricular hypertrophy (LVH) or conduction abnormalities) or evolving ST segment to $\mathrm{T}$ - wave changes in two contiguous leads or new left bundle branch block or ST segment elevation requiring thrombolysis or percutaneous coronary intervention (PCI) and cardiac markers (troponins or creatinine kinase muscle/brain $(\mathrm{CKMB}))$ in the necrosis range. Repeat coronary revascularization: new CABG procedure or PCI associated with documented ischemia by stress testing (ECG, echo, or nuclear) and graft failure or new culprit lesion) $=70 \%$ luminal stenosis). Deep sternal wound infections: bonerelated or any drainage of purulent material from the sternotomy wound and instability of the sternum.

\section{Results}

A total of 320 patients were enrolled and were randomly assigned to either off-pump CABG $(n=158$ patients $)$ or onpump CABG ( $n=162$ patients). Of 320 patients, 318 patients at 1 month and 316 patients at 3 months survived and were analyzed for MACCE. Among the survivors, 239 (75.6\%) patients (120 in off-pump group and 119 in on-pump group) underwent graft angiographic evaluation (MDCT in 190 patients and CAG in 49 patients at 3 months (Fig. 1) and angiographic evaluation was declined by 77 survivors.

Baseline variables, intraoperative (Table 1) and postoperative variables (Table 2) were comparable between the groups. The incidence of asymptomatic carotid artery stenosis was $0.63 \%$ (1 patient) in off-pump and $0.62 \%$ (1 patient) in on-pump group, $p=1.00$ in our study (Table 1). All patients in the trial had EF $\geq$ $40 \%$. Euroscore II was calculated for all patients and the median score is less than 1 (off-pump group 0.98 and on-pump group 0.98 ) which indicates a low-risk population in both groups. Two patients $(1.27 \%)$ were converted from off-pump to on-pump $\mathrm{CABG}$ and none was converted from on-pump to off-pump technique. The results were analyzed as intention to treat analysis. A total of 1137 grafts were used in 320 patients. The median number of grafts per patient in off-pump was $3.00(\mathrm{Q} 1: 3.00$ and Q3:4.00) vs on-pump 4.00 (Q1:3.00 to Q3:4.00), and mean number of grafts/patient was off-pump $3.45 \pm 0.75$ vs on-pump 3.64 $\pm 0.70)(p=0.01)$ (Table 1). One hundred forty-nine $(94.30 \%)$ patients received left internal thoracic artery (LITA) graft in offpump and 153 (94.44\%) in on-pump CABG group, $p=0.95 ; 22$ (13.92\%) patients received right ITA graft in the off-pump and $17(10.49 \%)$ in on-pump group, $p=0.34$. A total of $90(28 \%)$ patients received two or more arterial grafts (right internal thoracic artery (RITA)/radial artery). Right ITA in 39 patients and as in situ graft in 15 patients and as a free graft in 24 patients. There was no significant difference in the number of sequential anastomoses between the two groups $(25.95 \%$ grafts in off-pump and $23.78 \%$ in on-pump group; $p=0.46$ ). The distribution of grafts among various territories is mentioned in (Table 3). No difference was observed between the groups in terms of index of completeness of revascularization (number of grafts performed divided by number of grafts intended) 0.98 vs $1.00(p=0.8)$.

A total of four deaths occurred in the study. One mortality occurred in off-pump group (postoperative period) and 3 in on-pump group (1 postoperative period and 2 at 3 months). Three deaths were due to noncardiovascular cause and one due to pneumonia. There is no significant difference in mortality at 3 months between off-pump $(0.63 \%)$ and on-pump groups $(1.85 \%)$ odds ratio: $(0.33$, CI $0.03-3.28, p=0.62)$. There was no significant difference between the groups in the outcome of nonfatal MI [none in off-pump and $1.85 \%$ (3 patients) in on-pump group $(p=0.24)$, CVS $[0.00 \%$ in offpump and $1.85 \%$ ( 3 patients) in on-pump group $(p=0.24)$. Cumulative combined MACCE in off-pump group (0.63\%) was significantly lower than on-pump group (5.55\%) with an odds ratio of 0.108 (CI $0.01-0.86, p=0.01$ ). At 3 months follow-up, off-pump CABG was associated with a fewer MACCE compared to on-pump CABG (Table 4).

\section{Graft patency}

At 3 months, 316 patients survived and all were asymptomatic. Among these patients, 239 patients (75.6\%) (120 patients in off-pump group and 119 patients in on-pump group) turned up for graft evaluation. Of the 239 patients ( 849 grafts), 190 patients (684 grafts) underwent graft evaluation by MDCT [off-pump; 96 patients (339 grafts) and on-pump; 94 patients (345 grafts)] and 49 patients (165 grafts) [(off-pump; 24patients ( 81 grafts) and on-pump; 25 patients (84 grafts)] underwent catheter CAG. The modality of graft evaluation was not uniform due to non-availability of MDCT facility at some centers where the graft evaluation was done by catheter CAG. The baseline characteristics were comparable between patients who underwent graft evaluation and who declined graft evaluation. However, the patients who underwent graft evaluation are younger than the patients who declined graft evaluation $(57.93 \pm 7.18$ vs $59.85 \pm 6.89, p=0.03)$ (Table 5).

The graft evaluation was made similar to Fitzgibbon's grading (A, $\mathrm{B}$, and $\mathrm{O}$ grade grafts). The analysis was made by comparing A grade (excellent patency) grafts vs $\mathrm{B}$ and $\mathrm{O}$ grade (stenosed and occluded) grafts. In off-pump group (120 patients) out of 420 grafts, $366(87.1 \%$ ) grafts were grade A (excellent patency) grafts and in on-pump group (119 patients) out of 420 grafts, 376 $(87.6 \%)$ grafts were grade A (excellent patency) grafts $(p=$ 0.82 ). There was no significant deference in overall patency rates between the two techniques (Fig. 2). The analysis was also made comparing $\mathrm{A}$ and $\mathrm{B}$ vs $\mathrm{O}$ grade grafts. In on-pump group out of 429 grafts, 393 (91.6\%) were grade A and B grafts and in offpump group out of 420 grafts, $377(89.76 \%)$ grafts were grade A and B grafts $(p=0.3)$ (Fig. 3). 
Study period March 2016 to March 2017

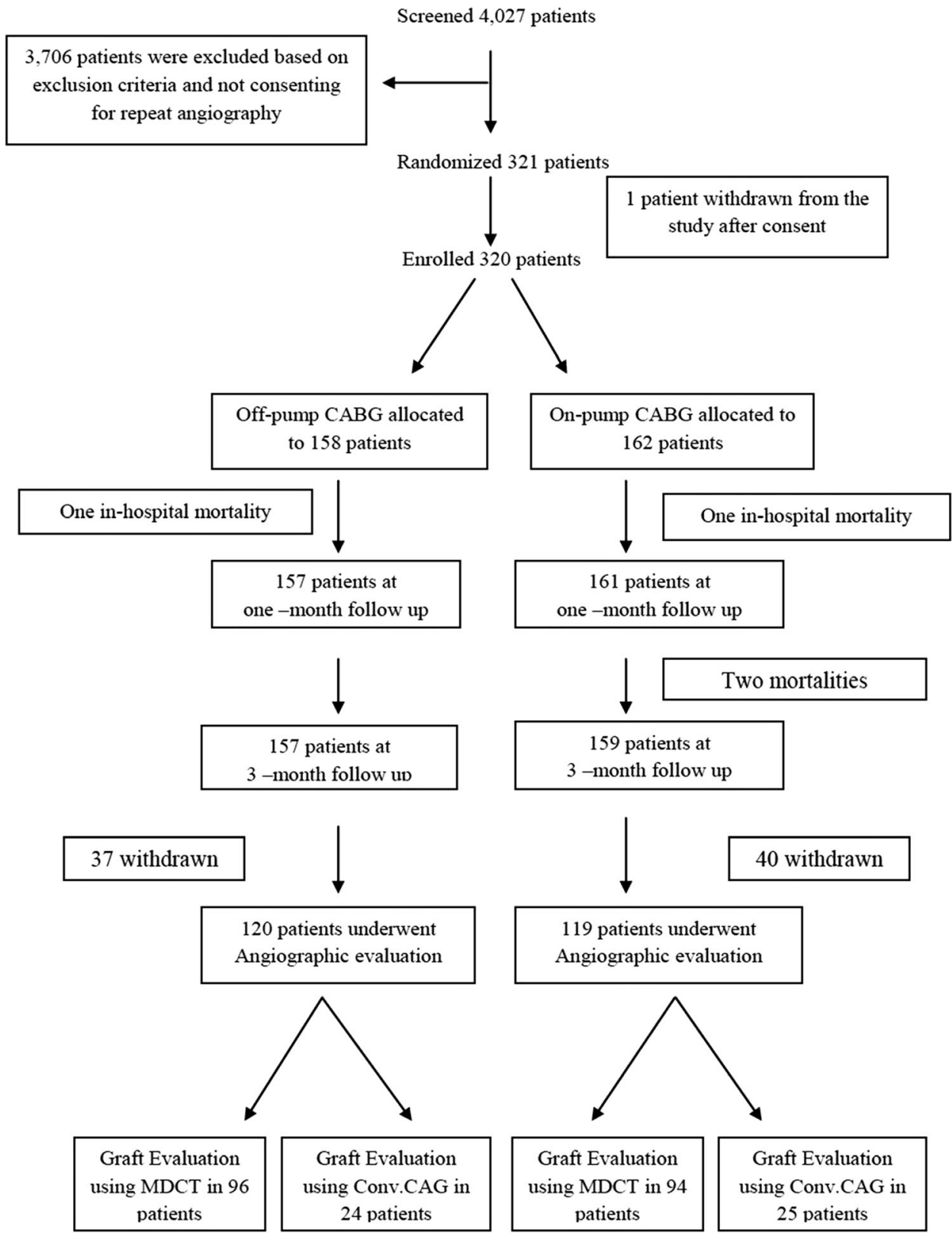

Fig. 1 Study flow chart

The comparison between A grade grafts vs $\mathrm{B}$ and $\mathrm{O}$ grade grafts showed that there was no significant difference in the patency rates of various bypass conduits [LITA: off-pump 118/129 (91.4\%) vs on-pump 118/127 (92.9\%), $(p=0.66)$; RITA: off-pump 23/28 (82.1\%) vs on-pump 18/22 $(81.8 \%),(p=0.97)$; radial artery (RA) graft: off-pump 38/45 (84.4\%) vs on-pump 38/46 $(82.6 \%),(p=0.81)$; saphenous vein graft (SVG): offpump 187/218 (85.8\%) vs on-pump 202/234 (86.3\%, $(p=0.86)]$ between the groups. Among the 3 coronary artery territories, patency rates of grafts were also similar [left anterior descending artery (LAD) territory: off-pump 147/165 (89.0\%) vs on-pump 152/167 (91.0\%), $(p=0.55)$; left circumflex artery (LCx) territory: off-pump 130/148 (87.4\%) vs on-pump 136/153 $(88.9 \%),(p=0.77)$, and right coronary artery (RCA) territory: off-pump 89/107 (83.1\%) vs on-pump 88/108 (80.7\%), $(p=0.64)$ ] (Table 6) and (Fig. 2).

When comparison was made between $\mathrm{A}$ and $\mathrm{B}$ grade grafts vs $\mathrm{O}$ grade grafts, there was no significant difference in the patency rates of various bypass conduits. [LITA: off-pump $122 / 129(94.5 \%)$ vs on-pump 122/127 $(96.06 \%),(p=0.57)$; 
Table 1 Baseline and intra-operative variables compared between off-pump and on-pump CABG

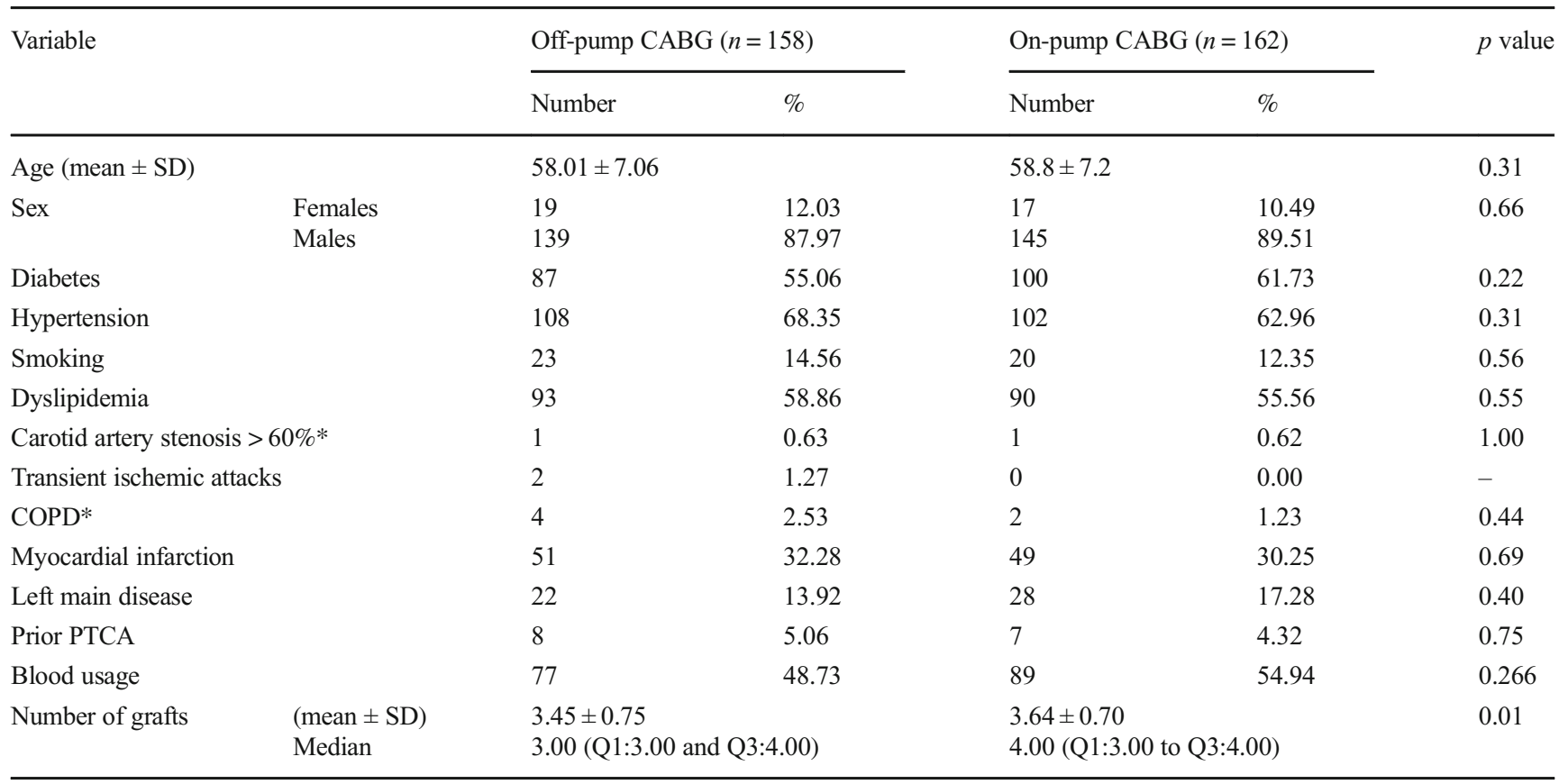

In off-pump CABG, conversion was done in 2 patients $(1.27 \%)$

In on-pump CABG, means of CPB time and aortic cross clamp time were $87.54 \pm 30.76$ and $52.93 \pm 17.71$ min respectively

*Fisher's exact test was used

$C A B G$, coronary artery bypass grafting; $C O P D$, chronic obstructive pulmonary disorder; $C P B$, cardiopulmonary bypass; $I A B P$, intra-aortic balloon pump; NYHA, New York Heart Association; PTCA, percutaneous transluminal coronary angioplasty

RITA: off-pump 23/28 (82.1\%) vs on-pump 18/22 (81.8\%), ( $p=0.97)$; RA graft: off-pump 39/45 (86.67\%) vs on-pump 41/ $46(89.13 \%),(p=0.71)$; SVG: off-pump 193/218 (88.53\%) vs on-pump 212/234 (90.6\%), $(p=0.47)]$ between the groups. Among the 3 coronary artery territories, patency rates of grafts were also similar [LAD territory: off-pump 152/165 (92.12\%) vs

Table 2 In-hospital outcomes compared between off-pump and on-pump CABG

\begin{tabular}{|c|c|c|c|c|c|}
\hline \multirow[t]{2}{*}{ Variable } & \multicolumn{2}{|c|}{ Off-pump CABG $(n=158)$} & \multicolumn{2}{|c|}{ On-pump CABG $(n=162)$} & \multirow[t]{2}{*}{$p$ value } \\
\hline & Number & $\%$ & Number & $\%$ & \\
\hline Re-exploration* & 4 & 2.53 & 5 & 3.09 & $>0.99$ \\
\hline Intra and post-operative IABP* & 2 & 1.27 & 6 & 3.70 & 0.28 \\
\hline Post-operative CVA & 0 & 0.00 & 0 & 0.00 & - \\
\hline AKI requiring RRT & 0 & 0.00 & 0 & 0.00 & - \\
\hline Pulmonary complications & 0 & 0.00 & 3 & 1.85 & - \\
\hline GI complications & 0 & 0.00 & 1 & 0.62 & - \\
\hline Post-operative atrial fibrillation & 15 & 9.49 & 9 & 5.56 & 0.18 \\
\hline DSWI* & 1 & 0.63 & 2 & 1.23 & $>0.99$ \\
\hline Post-operative MI & 0 & 0.00 & 0 & 0.00 & - \\
\hline Re-revascularization & 0 & 0.00 & 0 & 0.00 & - \\
\hline ICU stay $($ mean $\pm \mathrm{SD})$ & $2.75 \pm 2.12$ & & $2.74 \pm 1.83$ & & 0.87 \\
\hline Ward stay $($ mean $\pm \mathrm{SD})$ & $4.02 \pm 1.09$ & & $4.14 \pm 1.44$ & & 0.47 \\
\hline Death* & 1 & 0.63 & 1 & 0.62 & $>0.99$ \\
\hline
\end{tabular}

*Fisher's exact test was used

$A K I R R T$, acute kidney injury requiring renal replacement therapy; $D S W I$, deep sternal wound infection; GI, gastrointestinal; IABP, intra-aortic balloon pump; $I C U$, intensive care unit; $M I$, myocardial infarction 
Table 3 Distribution of grafts to various coronary artery territories

Graft distribution (1137 grafts) in the entire cohort of patients (320)

Graft distribution (849 grafts) in the patients (239) underwent graft evaluation

\begin{tabular}{|c|c|c|c|c|c|c|c|}
\hline Conduits & Territories* & Off-pump CABG & On-pump CABG & Conduits & Territories* & Off-pump CABG & On-pump CABG \\
\hline \multirow[t]{3}{*}{ LITA (347) } & LAD (322) & 152 & 170 & \multirow[t]{3}{*}{ LITA (256) } & LAD (236) & 116 & 120 \\
\hline & LCx (19) & 15 & 4 & & LCx (16) & 12 & 4 \\
\hline & $\mathrm{RCA}(6)$ & 3 & 3 & & $\mathrm{RCA}(4)$ & 1 & 3 \\
\hline \multirow[t]{3}{*}{ RITA (73) } & LAD (15) & 10 & 5 & \multirow[t]{3}{*}{ RITA (50) } & LAD (11) & 7 & 4 \\
\hline & LCx (41) & 19 & 22 & & LCx (26) & 13 & 13 \\
\hline & RCA (17) & 9 & 8 & & RCA (13) & 8 & 5 \\
\hline \multirow[t]{3}{*}{ RA (115) } & LAD (7) & 5 & 2 & \multirow[t]{3}{*}{ RA (91) } & $\operatorname{LAD}(6)$ & 5 & 1 \\
\hline & LCx (59) & 29 & 30 & & $\mathrm{LCx}(48)$ & 22 & 26 \\
\hline & RCA (49) & 24 & 25 & & RCA (37) & 18 & 19 \\
\hline \multirow[t]{3}{*}{ SVG (602) } & LAD (109) & 48 & 61 & \multirow{3}{*}{$\begin{array}{l}\text { SVG } \\
(452)\end{array}$} & LAD (79) & 37 & 42 \\
\hline & LCx (261) & 120 & 141 & & LCx (200) & 94 & 106 \\
\hline & RCA (232) & 113 & 119 & & RCA (173) & 87 & 86 \\
\hline Total conduits & Total territories* & 547 & 590 & Total conduits & Total territories & 420 & 429 \\
\hline 1137 & 1137 & & & 849 & 849 & & \\
\hline
\end{tabular}

*Territories: LAD (LAD+D1 + D2 + D3)

LCx (ramus intermedius, OM1, OM2, OM3, LPDA, distal circumflex)

$R C A$, (distal RCA, Mid RCA, PDA, PLVB); $C A B G$, coronary artery bypass grafting; $D$, diagonal; $L A D$, left anterior descending artery; $L C x$, left circumflex artery; LITA, left internal thoracic artery; $L P D A$, left posterior descending artery; PDA, posterior descending artery; PLVB, postero lateral ventricular branch; $R A$, radial artery; $R C A$, right coronary artery; $R I T A$, right internal thoracic artery; $S V G$, saphenous vein graft

on-pump 157/167 (94.01\%), ( $p=0.49)$; LCx territory: off-pump $133 / 148(89.86 \%)$ vs on-pump 141/153 (92.15\%), $(p=0.48)$, and RCA territory: off-pump 92/107 (85.98\%) vs on-pump 95/ $109(87.15 \%),(p=0.8)]$ between the groups .

\section{Analysis for non-inferiority in terms of graft patency in off-pump CABG}

Of 119 patients in on-pump CABG group who underwent graft evaluation, $111(93 \%)$ patients had grade A grafts and of 120 patients in off-pump CABG group, and $113(94 \%)$ patients had grade A grafts. Of 429 grafts in on-pump CABG group, 376 $(87 \%)$ grafts were grade A grafts and of 420 grafts in off-pump
CABG group 366 (87\%) grafts were grade A grafts (Table 7). The results show that off-pump CABG is non-inferior to onpump CABG with a significant $p$ value $(p=0.0001)$, thus rejecting the null hypothesis (off-pump CABG is inferior to onpump CABG).

\section{Discussion}

Graft occlusion is one of the major determinants of clinical prognosis after $\mathrm{CABG}$ and is measured by reintervention rates and survival. In countries like India, Japan, and Brazil with an off-pump CABG adoption

Table 4 Cumulative MACCE between off-pump and on-pump CABG at 3 months

\begin{tabular}{|c|c|c|c|c|c|c|c|c|}
\hline Variables & Technique of CABG (no of patients) & Yes $n(\%)$ & No $n(\%)$ & Rate & Risk ratio $(95 \% \mathrm{CI})$ & Odds & Odds ratio $(95 \% \mathrm{CI})$ & $p$ value \\
\hline Mortality & $\begin{array}{l}\text { Off-pump CABG (158) } \\
\text { On-pump CABG (162) }\end{array}$ & $\begin{array}{l}1(0.63) \\
3(1.85)\end{array}$ & $\begin{array}{l}157(99.36) \\
159(98.14)\end{array}$ & $\begin{array}{l}0.0063 \\
0.0185\end{array}$ & $0.34(0.03-3.25)$ & $\begin{array}{l}0.064 \\
0.0018\end{array}$ & $0.337(0.03-3.28)$ & 0.62 \\
\hline Non-fatal MI & $\begin{array}{l}\text { Off-pump CABG (158) } \\
\text { On-pump CABG (162) }\end{array}$ & $\begin{array}{l}0(0.00) \\
3(1.85)\end{array}$ & $\begin{array}{l}158(100.00) \\
159(98.14)\end{array}$ & $\begin{array}{l}0 \\
0.018\end{array}$ & 0 & $\begin{array}{l}0 \\
0.0189\end{array}$ & 0 & 0.24 \\
\hline CVA & $\begin{array}{l}\text { Off-pump CABG (158) } \\
\text { On-pump CABG (162) }\end{array}$ & $\begin{array}{l}0(0.00) \\
3(1.85)\end{array}$ & $\begin{array}{l}158(100.00) \\
159(98.14)\end{array}$ & $\begin{array}{l}0 \\
0.018\end{array}$ & 0 & $\begin{array}{l}0 \\
0.0189\end{array}$ & 0 & 0.24 \\
\hline Total MACCE & $\begin{array}{l}\text { Off-pump CABG (158) } \\
\text { On-pump CABG (162) }\end{array}$ & $\begin{array}{l}1(0.63) \\
9(5.55)\end{array}$ & $\begin{array}{l}157(99.36) \\
153(0.94)\end{array}$ & $\begin{array}{l}0.006 \\
0.055\end{array}$ & $0.11(0.01-0.88)$ & $\begin{array}{l}0.064 \\
0.058\end{array}$ & $0.108(0.01-0.86)$ & 0.01 \\
\hline
\end{tabular}

$C A B G$, coronary artery bypass grafting; $C V A$, cerebrovascular accident; $M A C C E$, major adverse cardiac and cerebrovascular events (mortality, non-fatal MI; CVA); Rate, proportion in group with condition present 
Table 5 Comparison of baselines variables between the patients in whom angio is performed and not performed

\begin{tabular}{|c|c|c|c|c|}
\hline & & Angio not done (81) $n(\%)$ & Angio done (239) $n(\%)$ & $p$ value \\
\hline Age $($ mean $\pm \mathrm{SD})$ & & $59.85 \pm 6.89$ & $57.93 \pm 7.18$ & 0.037 \\
\hline Sex & $\begin{array}{l}\text { Female } \\
\text { Male }\end{array}$ & $\begin{array}{l}12(14.81) \\
69(85.19)\end{array}$ & $\begin{array}{l}24(10.04) \\
215(89.96)\end{array}$ & 0.24 \\
\hline Smoking & $\begin{array}{l}\text { No } \\
\text { Yes }\end{array}$ & $\begin{array}{l}69(85.19) \\
12(14.81)\end{array}$ & $\begin{array}{l}208(87.03) \\
31(12.97)\end{array}$ & 0.67 \\
\hline Hypertension & $\begin{array}{l}\text { No } \\
\text { Yes }\end{array}$ & $\begin{array}{l}26(32.10) \\
55(67.90)\end{array}$ & $\begin{array}{l}84(35.15) \\
155(64.85)\end{array}$ & 0.61 \\
\hline Diabetes mellitus & $\begin{array}{l}\text { No } \\
\text { Yes }\end{array}$ & $\begin{array}{l}34(41.98) \\
47(58.02)\end{array}$ & $\begin{array}{l}99(41.42) \\
140(58.58)\end{array}$ & 0.93 \\
\hline Dyslipidemia & $\begin{array}{l}\text { No } \\
\text { Yes }\end{array}$ & $\begin{array}{l}40(49.38) \\
41(50.62)\end{array}$ & $\begin{array}{l}9(40.59) \\
142(59.41)\end{array}$ & 0.16 \\
\hline COPD & $\begin{array}{l}\text { No } \\
\text { Yes }\end{array}$ & $\begin{array}{l}80(98.77) \\
1(1.23)\end{array}$ & $\begin{array}{l}234(97.91) \\
5(2.09)\end{array}$ & $>0.99 *$ \\
\hline Carotid artery stenosis $>60 \%$ & $\begin{array}{l}\text { No } \\
\text { Yes }\end{array}$ & $\begin{array}{l}80(98.77) \\
1(1.23)\end{array}$ & $\begin{array}{l}238(99.58) \\
1(0.42)\end{array}$ & $0.44 *$ \\
\hline Transient ischemic attack & $\begin{array}{l}\text { No } \\
\text { Yes }\end{array}$ & $\begin{array}{l}81(100.00) \\
0(0.00)\end{array}$ & $\begin{array}{l}237(99.16) \\
2(0.84)\end{array}$ & $>0.99 *$ \\
\hline Cerebro vascular accident & $\begin{array}{l}\text { No } \\
\text { Yes }\end{array}$ & $\begin{array}{l}73(97.53) \\
2(2.47)\end{array}$ & $\begin{array}{l}235(98.33) \\
4(1.67)\end{array}$ & $0.64 *$ \\
\hline Myocardial infarction & $\begin{array}{l}\text { No } \\
\text { Yes }\end{array}$ & $\begin{array}{l}59(72.84) \\
22(27.16)\end{array}$ & $\begin{array}{l}161(67.36) \\
78(32.64)\end{array}$ & 0.35 \\
\hline Prior PTCA & $\begin{array}{l}\text { No } \\
\text { Yes }\end{array}$ & $\begin{array}{l}78(96.30) \\
3(3.70)\end{array}$ & $\begin{array}{l}227(94.98) \\
12(5.02)\end{array}$ & $0.76^{*}$ \\
\hline Left main disease & $\begin{array}{l}\text { No } \\
\text { Yes }\end{array}$ & $\begin{array}{l}68(83.95) \\
13(16.05)\end{array}$ & $\begin{array}{l}202(84.52) \\
37(15.48)\end{array}$ & 0.90 \\
\hline Surgery & $\begin{array}{l}\text { Off-pump } \\
\text { On-pump }\end{array}$ & $\begin{array}{l}38(46.91) \\
43(53.09)\end{array}$ & $\begin{array}{l}120(50.21) \\
119(49.79)\end{array}$ & 0.60 \\
\hline
\end{tabular}

*Fisher exact test used

$C O P D$, chronic obstructive pulmonary disorder; PTCA, percutaneous transluminal coronary angioplasty

Fig. 2 Graft patency rates between off-pump and on-pump CABG
FitzGibbon's A grade grafts (excellent patency) - On-pump CABG $\square$ Off-pump CABG

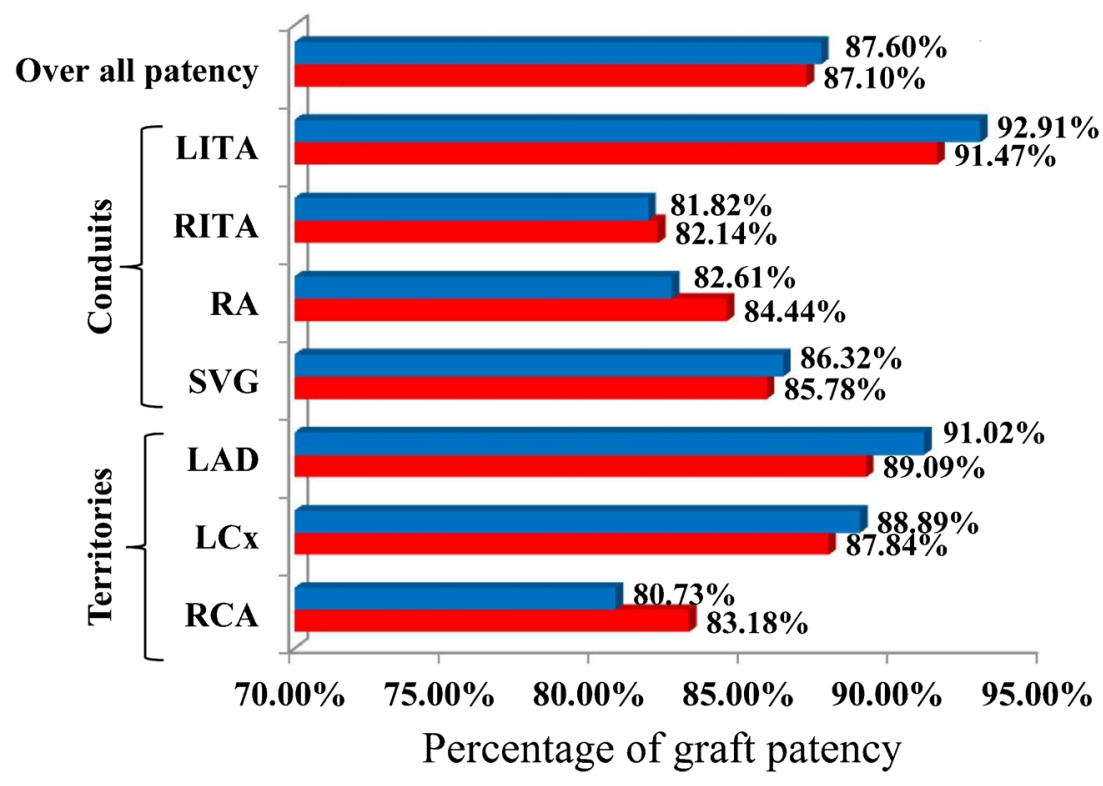


Fig. 3 Overall graft patency showing patency rates of $A$ vs $B$ and $\mathrm{O}$ and $\mathrm{A}$ and $\mathrm{B}$ vs $\mathrm{O}$

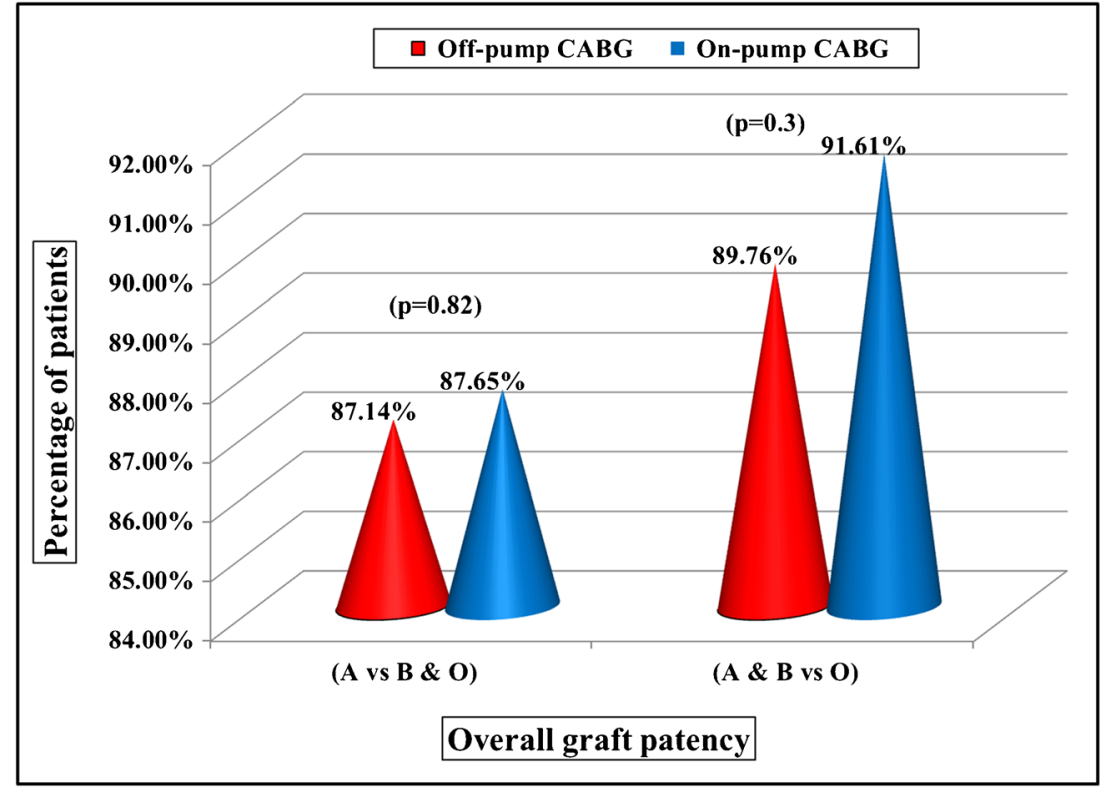

rate in excess of $50 \%[2,7]$, it is prudent to query the non-inferiority of this technique as compared with onpump CABG. Angiographic evaluation was performed at 3 months considering that edema at the site of anastomosis would resolve by that time and it would be too early to have graft attrition. In the present study, the graft patency rates were similar between off-pump and on-pump technique as in the Surgical Management of Arterial Revascularization Therapies (SMART) trial [6] where angiography was done at 30 days and at 1 year. But, our study differs from the angiographic patency rates of Khan et al. [3] and ROOBY trial [1] which reported lower patency rates with off-pump technique. The possible reason for lower graft patency in offpump technique in ROOBY trial [1] was thought to be the inexperience of the surgeons involved in the study as evidenced by a higher conversion rates from off-pump to on-pump technique (12.7\%). In our study, the conversion rate was $1.27 \%$. There has been no significant difference in the index of completeness of revascularization between the groups in our study though higher rates of incomplete revascularization were reported by several authors $[10,11]$. This can also be attributed to the experience of the surgeons who participated in the study. The graft patency rates at 3 months with various bypass conduits among the different coronary territories were similar between off and on-pump groups, which coincide with the results of Puskas and colleagues [6] and Magee et al. [12] who reported similar patency rates at 1 year.

Our study is concurrent with Diegeler et al. [13] in GOPCABEtrial, Lamy et al. [14] in CORONARY trial, and Taggart et al. [15] in Arterial Revascularization Trial (ART)

Table 6 Rates of grade A grafts (excellent patency similar to Fitzgibbon's grading) in various conduits and territories

\begin{tabular}{lllll}
\hline Conduit & Grade A grafts/total grafts (percentage) & $\begin{array}{l}\text { Off-pump CABG } \\
\text { Grade A grafts/total grafts (percentage) }\end{array}$ & $\begin{array}{l}\text { On-pump CABG } \\
\text { Grade A grafts/total grafts (percentage) } \\
118 / 127(92.91 \%)\end{array}$ & $p$ value \\
LITA & $236 / 256(92.10 \%)$ & $118 / 129(91.47 \%)$ & $18 / 22(81.82 \%)$ & 0.66 \\
RITA & $41 / 50(82.0 \%)$ & $23 / 28(82.14 \%)$ & $38 / 46(82.61 \%)$ & 0.97 \\
RA & $76 / 91(83.50 \%)$ & $38 / 45(84.44 \%)$ & $202 / 234(86.32 \%)$ & 0.81 \\
SVG & $389 / 452(86.06 \%)$ & $187 / 218(85.78 \%)$ & $376 / 429(87.65 \%)$ & 0.86 \\
All conduits & $742 / 849(87.39 \%)$ & $366 / 420(87.14 \%)$ & On-pump CABG & 0.82 \\
Territories & Grade A grafts/total grafts (percentage) & Off-pump CABG & Grade A grafts/total grafts (percentage) & $152 / 167(91.02 \%)$ \\
& & Grade A grafts/total grafts (percentage) & 0.55 \\
LAD & $299 / 332(90.06 \%)$ & $147 / 165(89.09 \%)$ & $136 / 153(88.89 \%)$ & 0.77 \\
LCX & $266 / 301(88.37 \%)$ & $130 / 148(87.84 \%)$ & $88 / 108(80.73 \%)$ & $376 / 429(87.65 \%)$ \\
RCA & $177 / 216(81.94 \%)$ & $89 / 107(83.18 \%)$ & 0.64 \\
All territories & $742 / 849(87.39 \%)$ & $366 / 420(87.14 \%)$ & 0.82 \\
\hline
\end{tabular}

$C A B G$, coronary artery bypass grafting; $L A D$, left anterior descending artery; $L C x$, left circumflex artery; LITA, left internal thoracic artery; $R A$, radial artery; $R C A$, right coronary artery; RITA, right internal thoracic artery; $S V G$, saphenous vein graft 
Table 7 Non-inferiority test results for all grafts and subjects

\begin{tabular}{|c|c|c|c|c|c|c|c|c|c|c|}
\hline \multirow[t]{2}{*}{ Variable } & \multicolumn{2}{|c|}{ Off-pump group } & \multicolumn{2}{|c|}{ On-pump group } & \multicolumn{2}{|c|}{$\begin{array}{l}95 \% \text { CI for } \\
\text { difference }\end{array}$} & \multicolumn{2}{|c|}{$\begin{array}{l}\text { NI margin (\% of on-pump } \\
\text { group) }\end{array}$} & \multirow[t]{2}{*}{$p$ value } & \multirow[t]{2}{*}{ Non-inferiority attained (yes/no) } \\
\hline & Total & Patent $n(\%)$ & Total & Patent $n(\%)$ & Low & Upper & & & & \\
\hline \multirow[t]{2}{*}{ Grafts } & 420 & $366(87)$ & 429 & $376(87)$ & -0.050 & 0.040 & 10 & -0.0876 & 0.0001 & Yes \\
\hline & & & & & & & 5 & -0.0438 & 0.0444 & Yes \\
\hline \multirow[t]{2}{*}{ Subjects } & 120 & $113(94)$ & 119 & $111(93)$ & -0.053 & 0.070 & 10 & -0.0932 & $<0.0006$ & Yes \\
\hline & & & & & & & 5 & -0.0466 & $<0.0385$ & Yes \\
\hline
\end{tabular}

$C I$, confidence interval, $n$, sample of population; $N I$, non-inferiority

which reported no significant difference in the rate of composite outcome of death at 30 days. In a recent report, Chikwe et al. [16] reported that off-pump CABG was associated with an increased incidence of incomplete revascularization, need for repeated revascularization, and mortality in early outcomes and at 10 years compared with on-pump CABG. However, they have not assessed the graft patency in their patients. But, quite a few grafts that fail, do so with little immediate clinical consequence to the patient. Our study demonstrated marginally lower overall graft patency rates (excellent grafts 87\%), which may be attributable to complex coronary anatomy with higher Syntax score in our patient population, and smaller coronary artery size. Some patients with target artery stenosis of 70 to $90 \%$ sub critical stenosis have received RITA graft to posterior descending artery (PDA)/distal RCA as the most distant distal anastomoses. This could have probably contributed to the lower graft patency of RITA grafts. Similar patency rates of sequentially anastomosed RITA graft to PDA were reported by Glineur et al. [17]. Further, this study analyzed grade $\mathrm{A}$ grafts as patent grafts and $\mathrm{B}$ and $\mathrm{O}$ grade grafts as occluded grafts in contrast to other studies which compared A and B grade grafts vs $O$ grafts $[1,6,18,19]$. The cohorts of patients are being followed up yearly for clinical evaluation and angiographic graft evaluation is contemplated at 5 years.

\section{Limitations}

The evaluation of graft patency was not uniform and was done by either MDCT or catheter CAG. In $80 \%$ of patients, graft evaluation was done by MDCT, which despite its accuracy for detection of bypass graft occlusions does not provide information on graft flow but was used in recent large studies comparing late offpump and on-pump graft patency trials [20, 21]. Less than $10 \%$ of screened patients were enrolled in the study due to difficulty in obtaining the consent for early angiographic evaluation. Only $75 \%$ of patients (849 grafts) were subjected to angiographic graft evaluation. Only low-risk patients were enrolled in this study.

\section{Conclusions}

The study demonstrates that there is no significant difference in overall graft patency rates at 3 months between off-pump and on-pump CABG groups when performed by experienced surgeons who have a higher adoption of this strategy. Further, this study shows no difference in the graft patency among the 3 coronary artery territories and the different types of conduits between off-pump and on-pump CABG patients. At 3 months follow-up, off-pump CABG was associated with a fewer MACCE compared to on-pump CABG.

Acknowledgments We thank Dr. Sruthi Kalyan, MD and Dr. Ravi Battina, MD Radiologists of Star Hospitals, Hyderabad, and Dr. V Ramachandra Raju Pusapati, MD, DM, Cardiologist of Star Hospitals, Hyderabad. We also thank Mr. A. Nadamuni Naidu, M.Sc (Stat), Trustee, Sajja Heart Foundation, Hyderabad. We thank all the co-ordinators from various institutions: Mr. Mamidala Parusharamulu of Star Hospitals, Hyderabad, Mr. Arnab Naik of Medica Superspeciality, Kolkata, MS. Shashirekha of Krishna Institute of Medical Sciences, Hyderabad, MS. Mahalakshmi Shanmugam of G Kuppuswamy Naidu Memorial Hospital, Coimbatore, Dr. Reenali Bariya of DDMM Heart Institute, Gujarat, Dr. Upendra Bhalero of Fortis Hospital, Mumbai.

\section{Compliance with ethical standards}

Conflict of interest The authors declare that they have no conflict of interest.

\section{Funding None.}

Research involving human participants and/or animals This study complies with the principles of The Declaration of Helsinki and was approved by the institutional ethics committee.

Informed consent Informed consent was obtained from all the patients.

Open Access This article is distributed under the terms of the Creative Commons Attribution 4.0 International License (http:// creativecommons.org/licenses/by/4.0/), which permits unrestricted use, distribution, and reproduction in any medium, provided you give appropriate credit to the original author(s) and the source, provide a link to the Creative Commons license, and indicate if changes were made. 


\section{References}

1. Shroyer AL, Grover FL, Hattler B, et al. On-pump versus off-pump coronary- artery bypass surgery. N Engl J Med. 2009;361:1827-37.

2. Mohr FW. To beat or not to beat? Form one size fits it all to an individual coronary revascularization strategy. Eur Heart J. 2010:31:2441-3.

3. Khan NE, De Sousa A, Mister R, et al. A randomized comparison of off-pump and on-pump multivessel coronary-artery bypass surgery. N Engl J Med. 2004;350:21-8.

4. Houlind K, Kjeldsen BJ, Madsen SN, et al. The impact of avoiding cardiopulmonary by-pass during coronary artery bypass surgery in elderly patients: the Danish On-pump Off-pump Randomisation Study (DOORS). Trials. 2009;10:47.

5. Widimsky P, Straka Z, Stros P, et al. One year coronary bypass graft patency. A randomized comparison between off-pump and onpump surgery. Angiographic results of the PRAGUE-4 trial. Circulation. 2004;110:3418-23.

6. Puskas JD, Williams WH, Mahoney EM, et al. Off-pump versus conventional coronary artery bypass grafting: Early and 1-year graft patency, cost and quality of life outcomes: a randomized trial. JAMA. 2004;291:1841-9.

7. Sajja LR. Sadasivan Oration: The journey of surgery for coronary artery disease in India: adoption, customization and innovation. Indian J Thorac Cardiovasc Surg. 2014;30:116-28.

8. Fitzgibbon GM, Kafka HP, Leach AJ, Keon WJ, Hooper GD, Burton JR. Coronary bypass graft fate and patient outcome: Angiographic follow-up of 5,065 grafts related to survival and reoperation in 1,388 patients during 25 years. J Am Coll Cardiol. 1996;28:616-26.

9. Sajja LR, Mannam G, Sompali S, et al. Does multi- vessel off-pump coronary artery bypass grafting reduce post-operative morbidity compared to on-pump CABG? Indian J Thorac Cardiovasc Surg. 2004;20:173-7.

10. Hu S, Zheng Z, Yuan X, et al. Increasing long-term major vascular events and resource consumption in patients receiving off-pump coronary artery bypass: a single- centre prospective observational study. Circulation. 2010;121:1800-8.

11. Sabik JF, Blackstone EH, Lytle BW, Houghtaling PL, Gillinov AM, Cosgrove DM. Equivalent midterm outcomes after off-pump and on-pump coronary surgery. J Thorac Cardiovasc Surg. 2004;127: $142-8$.

12. Magee MJ, Alexander JH, Hafley G, et al. Coronary artery bypass graft failure after on-pump and off-pump coronary artery bypass: findings from PREVENT IV. Ann Thorac Surg. 2008;85:494-9.

13. Diegeler A, Börgermann J, Kappert U, et al. Off-pump versus onpump coronary-artery bypass grafting in elderly patients. $\mathrm{N}$ Engl $\mathrm{J}$ Med. 2013;368:1189-98.

14. Lamy A, Devereaux PJ, Prabhakaran D, et al. Off-pump or onpump coronary-artery bypass grafting at 30 days. N Engl J Med. 2012;366:1489-97.

15. Taggart DP, Altman DG, Gray AM, et al. Effects of on-pump and off-pump surgery in the Arterial Revascularization Trial. Eur J Cardiothorac Surg. 2015;47:1059-65.

16. Chikwe J, Lee T, Itagaki S, Adams DH, Egorova NN. Long-term outcomes after off-pump versus on-pump coronary artery bypass grafting by experienced surgeons. J Am Coll Cardiol. 2018;72: 1478-86.

17. Glineur D, Hanet $\mathrm{C}$, D'hoore $\mathrm{W}$, et al. Causes of non-functioning right internal mammary used in a Y-graft configuration: insight from a 6-month systematic angiographic trial. Eur J Cardiothorac Surg. 2009;36:129-35.

18. Lingaas PS, Hol PK, Lundblad R, et al. Clinical and radiologic outcome of Off-Pump coronary surgery at 12 month follow-up: a prospective randomized trial. Ann Thorac Surg. 2006;81:2089-96.
19. Nathoe HM, van Dijk D, Jansen EW, et al. A comparison of onpump and off-pump coronary bypass surgery in low-risk patients. $\mathrm{N}$ Engl J Med. 2003;348:394 402.

20. Angelini GD, Culliford L, Smith DK, et al. Effects of on-and offpump coronary artery surgery on graft patency, survival, and health related quality of life: long-term follow -up of 2 randomised controlled trials. J Thorac Cardiovasc Surg. 2009;137:295-303.

21. Sousa Uva M, Cavaco S, Oliveira AG, et al. Early graft patency after off-pump and on-pump coronary bypass surgery: a prospective randomized study. Eur Heart J. 2010;31:2492-9.

Publisher's note Springer Nature remains neutral with regard to jurisdictional claims in published maps and institutional affiliations.

\section{Discussant 1 - Dr Praveen Kerala Varma, \\ Professor and Head of Cardio Thoracic Surgery, \\ Amrita Institute of Medical Sciences, \\ Kochi, India}

Question 1. There are important gaps between efficacy and effectiveness, efficacy meaning proof in a carefully controlled trial, and effectiveness meaning success in the circumstances of everyday life. In your study, OPCAB was found to be non-inferior to ONCAB; however the patients were carefully selected (low risk group) and operated in a controlled environment. Do you think that this is a major limitation of the study? Would it not be more appropriate to do a propensity matched retrospective study to mimic real-world setting?

Response: Efficacy and effectiveness according to dictionary are synonymous, meaning "the degree to which something is successful in producing a desired result". Our selection criteria and exclusions from the study were based purely on day to day practice and the ability of a surgeon participating in the study to choose either on or off-pump $\mathrm{CABG}$ in a given patient. In any given study there are exclusion criteria to enroll patients and to prove or disprove a research question. Hence, there is always selection bias to certain extent. In this study all of us set out to establish in Indian context whether there is any advantage of one method over the other CABG technique. Randomized trials are designed to eliminate selection bias, albeit with exclusion criteria, and collection of necessary data prospectively. However, retrospective observational study has the disadvantage of bias, even if it is propensity matched. Moreover, it has missing and inadequate data to draw conclusions.

Question 2. In your study the patency of grafts seemed to be less than reported in wider global literature. I am more concerned with the lower patency rates of RITA and radial artery compared to SVG. What do you think is the reason?

Response: The early graft patency / failure observed in this study is comparable with other studies reported in literature. The patency of arterial grafts generally depends on severity of the stenosis of the target artery - which determines the competitive flow, quality of anastomoses and distal run off. Early graft failure of RITA and RA grafts could be related to one or more of the above mentioned reasons. However, the graft failure rate is not higher than the reported rates in the literature.

Question 3. CTA has definite disadvantage to evaluate the distal portion of grafts. However upto $80 \%$ of grafts were evaluated using this technique. I will be interested to read your thoughts.

Response: CT coronary angiogram is currently recommended first choice of modality to investigate coronary bypass graft patency and coronary anomalies. In our study CTA with 128 slice scan was the preferred choice. However, at the centers where this investigative modality was not available ( $20 \%$ of cases), conventional angiography was performed. Moreover both were studied by an independent qualified and experienced Radiologist, who was blinded to on or off-pump technique. This assured equanimity and bias free interpretation. 
Question 4. Randomized controlled trials involving 2 different techniques performed by a single surgeon can create difficulties and are discouraged because even though the surgical community can be in equipoise, individual surgeons may have strong preferences over one technique over the other. Hence most surgical trials use expertise-based study where participants are randomized to surgeons with expertise in the allocated intervention. Do you think this could have been a better model?

Response: We do not agree with the opinion about surgeon's expertise in the performance of on or off-pump CABG. In fact all the surgeons who participated in the study are currently practicing both the techniques and do not exclusively depend on one type of operation. While preference could be one or other type of procedure, we do not have any doubt on the ability of individual surgeons who participated in the study.

Question 5. Do you think 3 months patency assessment is too short a time to assess the impact of the procedure?

Response: It is an established fact that angiograms performed within a few days of surgery showing poor flow in the grafts were shown to be fully patent at 6 weeks. This could be related to edema at the anastomotic site, hemodynamic status of the patient etc. All these issues would have been resolved by three months. Hence, grafts evaluation was done after 3 months of index surgery.

Question 6. Why did you specifically look at the graft patency as the primary end point? Why not clinically relevant end points like MACCE?

Response: Although about 1,50,000 CABG procedures using either on pump or off-pump technique are done per annum in India, graft patency rates supported by angiographic studies were never reported. The quality and longevity of patient's life depends on the graft patency. Hence, it was taken as our primary end point. However, MACCE data has been looked as secondary end point.

Discussant 2 - Dr Pradeep Narayan.

Senior Consultant CardiacSurgeon,

Rabindranath Tagore International Institute of Cardiac Sciences,

\section{Kolkata 700099, India}

Question 1. Generally coronary surgeons are either predominantly "offpump surgeons" or "on-pump surgeons". It is unusual for surgeons to carry out coronary revascularization using both techniques routinely. So it is difficult to understand how it was ensured that this criterion of " 250 procedures in each technique" was met by all participating surgeons. Did the researchers adhere to this requirement or was the overall experience and familiarity with both techniques taken as a reasonable, and in my view completely acceptable, compromise? Also do the researchers feel that adopting an expertise based model, in any given technique, as laid out in the CABG Off or On Pump Revascularization Study (CORONARY) would have been a better option for judging expertise?

Response: We accept that generally coronary surgeons are either predominantly "off-pump surgeons" or "on-pump surgeons". We included surgeons in this study who met the criteria of having performed 250 procedures in each technique in the preceding 3 years and had operative mortality $<3 \%$. The participating surgeons had overall experience and familiarity with both the techniques and had more than 20years of experience. Many of the surgeons had initially got trained in on-pump technique and later on adopted off-pump technique and had adequate experience with both the techniques.

Question 2. Another very important issue with regards to PROMOTE patency trial is using two different modalities to assess graft patency and is perhaps the most important confounder of the trial. Graft patency was assessed at 3 months by either 128 slice multidetector computed tomography (MDCT) or conventional catheter coronary angiography (CAG). There is no denying that 128 slice multidetector computed tomography (MDCT) is comparable to conventional angiography in terms of sensitivity and specificity. However, both the systems while being completely valid individually use a different system of evaluation. So how did the authors ensure that the graft evaluation performed by MDCT was made comparable to Fitzgibbon's grading of grafts (A, B, $\mathrm{O})$ ? Also, could the authors have chosen to analyze the findings of these two modalities separately?

Question 3. The argument provided by the authors in support of using both modalities is that "graft evaluation was not uniform due to nonavailability of MDCT facility at some centers where the graft evaluation was done by catheter CAG." However, this is inaccurate as the study was designed to evaluate patency at 3-months in all participants using conventional angiography as mentioned in the Clinical Trials Registry of India (CTRI/2017/10/010030) document enclosed with the manuscript. So why did the authors deviate from their original protocol?

Response for Q 2 \& 3: Initially we had planned conventional coronary angiography to evaluate the grafts in all patients and CTRI application was made. However, later on we felt that patients would be more comfortable with non-invasive MDCT angiography, so that the protocol was then revised and CTRI was informed. Unfortunately, some of the centers did not have facility to perform MDCT angiography and therefore we had to perform conventional coronary angiogram. Every effort was made by an experienced Radiologist to classify the CT images broadly in Fitzgibbon A, B \& O grades. However, we do admit it is an important limitation of our trial.

Question 4. One of the exclusion criteria that the authors mention in the protocol submission to CTRI is "contra-indications to off-pump CABG or on-pump CABG (calcified aorta, intramuscular LAD, calcified coronaries, small target vessels, resection of ventricular aneurysm)". As calcified aorta, intramuscular LAD and small target vessels can often only be identified intraoperatively (and thus post-randomization), did the authors remove these exclusion criteria in the actual trial? If they did apply these in the trial, were there any patients excluded from the trial using this criterion?

Response: Yes, it was an exclusion criteria which was mentioned in the trial. We did not exclude any of the patients using this criterion in the study.

Question 5. The authors calculated the required sample size as 310 patients (155 patients in each arm) and to compensate for eventual dropouts of $10 \%$ kept an enrolment target of 350 patients (175 patients in each arm). The sample size mentioned in the CTRI was even higher at 400. The study finally enrolled only 320 patients. What was the reason for truncating the recruitment of patients at 320 which was below their initial target of 350 ?

Response: We did intend to enroll 350 patients, but the study had no external funding. As a result we had to truncate the recruitment of patients at 320 , as we had already recruited more than the number of patients required for the study.

Question 6. The final issue relates to generalizability of the trial findings. The patient population in the trial setting was extremely low risk (EuroSCORE II being 0.98 in both arms). Do the authors feel that findings of this trial can be extrapolated to the population at large?

Response: Because this was the first randomized trial in this area which has not been explored previously in our country, we chose to include only low risk patients in the study. These patients may not represent entire cohort but these patients certainly form a substantial part of our routine workload. However, caution has to be exercised in extrapolating these results to the high risk patients. As studies in the past have already shown that off-pump may be superior in high risk patients, this could be a subject matter for another trial. 